\title{
ANALISIS KETERSEDIAAN TENAGA KESEHATAN DALAM CAPAIAN INDIKATOR KINERJA PUSKESMAS
}

\section{ANALYSIS OF HEALTH PERSONNEL AVAILABILITY IN THE ACHIEVEMENT OF HEALTH CENTERSHAS PERFORMANCE INDICATORS}

\author{
Mustara $^{1}$, Sri Nani Purwaningrum ${ }^{2}$ \\ ${ }^{1,2}$ Prodi Perekam Medis dan Informasi Kesehatan Poltekkes Kemenkes Tasikmalaya, \\ Email: mustara@dosen.poltekkestasikmalaya.ac.id
}

\begin{abstract}
ABSTRAK
Setiap pemerintah daerah memiliki kewajiban untuk menyelenggarakan pelayanan kesehatan yangindikasinyadapat dilihat dari capaian indikator standar pelayanan minimal bidang kesehatan. Penelitian ini bertujuan melihat hubungan jenisdan jumlah tenaga kesehatan dengan capaian indikator standar pelayanan minimal bidang kesehatan. Metode yang digunakan dalam penelitian ini yaitu penelitian kuantitatif dengan rancangan potong lintang.Populasi pada penelitian ini yaitu 57 puskesmas yang ada di Kabupaten Cirebon dengan teknik pengambilan sampel yaitu total populasi. Penelitian ini menggunakan sumber data sekunder dari profil kesehatan Kabupaten Cirebon tahun 2016. Hasil analisis univariat menunjukan bahwa7 puskesmas (12,3\%) memiliki capaian indikator kinerja tinggi sedangkan 50 puskesmas $(87,7 \%)$ rendah, sebanyak 11 puskesmas (19,3\%) memiliki jenis tenaga kesehatan yang lengkap dan 46 puskesmas $(80,7 \%)$ belum lengkap, sebanyak 4 puskesmas (7\%) jumlah tenaga kesehatan sudah sesuai dengan standar dan 53 puskesmas (93\%) belum sesuai dengan standar. Hasil uji fishemenunjukan ada hubungan antara jenis tenaga kesehatan ( $p$ value $=0,021$ ) dan jumlah tenaga kesehatan $(p$ value $=0,005)$ dengan capaian indikator standar pelayanan minimal bidang kesehatan. Disarankan penempatan tenaga kesehatan di puskesmas agar memperhatikan kelengkapan jenis dan kecukupan jumlah tenaga kesehatan.
\end{abstract}

Kata Kunci: Indikator, Standar Pelayanan Minimal, Ketenagaan

\begin{abstract}
Every local government has an obligation to provide health services whose can be seen from the achievement of standard indicators of minimum health services. This research aims to look at relationship between the types and number of health workers with the achievement of standard indicators of minimum health services. The method used is quantitative research with a cross-sectional design. The population was 57 health centers in Cirebon Local Government with sampling techniques is total population. This research used secondary data from the health profile of Cirebon Local Government in 2016. The results showed that 7 health centers (12.3\%) had high performance indicators while 50 health centers (87.7\%) were low, 11 health centers $(19.3 \%)$ have a complete type of health personnel and 46 health centers (80.7\%) are incomplete, as many as 4 health centers (7\%) the number of health workers is in accordance with the standards and 53 public health centers (93\%) are not in accordance with the standard. The results of fisher test showed that there was a relationship between types of health workers ( $p$ value $=0.021)$ and number of health workers ( $p$ value $=0.005)$ with achievement of standard indicators of minimum health services. Recommendationis that the placement of health workers in the health centershas to attention the completeness of the types and the adequacy of the number of health workers.
\end{abstract}




\section{Keyword: Indicator, Minimum Service Standards, Workforce}

\section{PENDAHULUAN}

Pembangunan kesehatan saat ini diselenggarakan melalui 3 pilar utama yaitu paradigma sehat, penguatan pelayanan kesehatan dan jaminan kesehatan nasional. Penguatan pelayanan kesehatan dilakukan dengan strategi peningkatan akses pelayanan kesehatan, optimalisasi sistem rujukan dan peningkatan mutu pelayanan kesehatan, menggunakan pendekatan continuum of care dan intervensi berbasis risiko kesehatan

Organisasi Puskesmas sebagai fasilitas pelayanan kesehatan tingkat pertama dalam melaksanakan pembangunan kesehatan tentunya harus optimal dan berkualitas. Pelayanan kesehatan berupa upaya kesehatan masyarakat (UKM) dan upaya kesehatan perorangan (UKP) merupakan tugas dan kewajiban yang harus dilaksanakan oleh puskesmas dengan mutu yang harus terjaga. Oleh karena itu pemerintah telah memberikan pedoman dan petunjuk teknis bagi puskesmas dalam rangka menjaga mutu pelayanannya tersebut. Salah satunya melalui pengukuran kinerja puskesmas yang beberapa diantaranya menggunakan variabel pencapaian standar pelayanan minimal.

Dengan demikian penilaian kinerja berdasarkan capaian indikator SPM perlu dilakukan oleh pemerintah daerah (Pemda) sebagai upaya untuk memonitoring institusi dalam mengukur kinerjanya. Hasil penilaian kinerja selanjutnya dapat digunakan untuk pembinaan dan evaluasi dalam upaya upaya dalam pembangunan kesehatan yang sudah dilakukan.

Berdasarkan hasil rieset fasilitas pelayanan kesehatan yang dilaksanakan tahun 2011 terlihat bahwa 94\% puskesmas di Indoneisa sudah melaksanakan enam (6) fungsi pelayanan kesehatan wajib meliputi: Promosi Kesehatan, Kesehatan Lingkungan, KIA/KB, Perbaikan Gizi Masyarakat, P2 Penyakit, dan Pengobatan. Jumlah seluruh tenaga yang bekerja di 8980 Puskesmas adalah 339,413 orang, dan berdasarkan pengelompokan di atas, maka distribusinya adalah sbb. : 7,4\% adalah tenaga medis, $65,9 \%$ tenaga keperawatan, $3,0 \%$ tenaga kefarmasian, $2,9 \%$ tenaga gizi, 3,3\% sanitarian, dan $1,2 \%$ promkes, $0,3 \%$ tenaga rekam medis dan $2 \%$ analis kesehatan, serta 13,9\% tenaga kesehaatan lainnya, termasuk tenaga adminsitrasi/pekarya. Tenaga perawat dan bidan yang merupakan tenaga inti di Puskesmas, Untuk masing-masing tenaga kesehatan bisa dilihat dari kisaran jumlah tenaga tersebut. Variasinya cukup lebar: 0-27 misalnya untuk dokter, artinya ada Puskesmas yang tidak ada dokter, akan tetapi dijumpai pula Puskesmas dimana dokternya sampai 27 orang. Gambaran disparitas yang sama terlihat juga untuk tenaga kesehatan lainnya[2]. SPM yang telah ditetapkan Pemerintah menjadi salah satu acuan bagi Pemerintahan Daerah untuk menyusun perencanaan dan penganggaran penyelenggaraan Pemerintahan Daerah. Pemerintah melaksanakan monitoring dan evaluasi atas penerapan SPM oleh Pemerintahan Daerah dalam rangka menjamin akses dan mutu pelayanan dasar kepada masyarakat. Bentuk pembinaan lain dari pemerintah terhadap pelaksanaan SPM berupa salah satunya penilaian prestasi kerja pencapaian SPM [3].

Hasil studi pendahuluan terhadap sasaran dan realisasi SPM Bidang Kesehatan tahun 2015 di Provinsi Jawa Barat dan Kabupaten Cirebon dengan analisis komparatif diketahui bahwa dari 22 indikator ada 3 indikator yang yang tidak bisa dianalisis dikarenakan angkanya tidak terisi dengan lengkap sedangkan 19 indikator lainnya terisi dengan lengkap. Dari 19 indikator tersebut hanya 8 indikator di Kabupaten Cirebon yang pencapaiannya melebihi pencapaian Provinsi Jawa Barat. Sedangkan 11 indikator lainnya berada dibawah pencapana Provinsi Jawa Barat.

SPM Bidang Kesehatan di Kabupaten/Kota merupakan akumulasi dari realisasi capaian SPM pada tingkat puskesmas. Peran tenaga kesehatan sangat penting dalam meyelenggarakan 
upaya kesehatan khususnya di puskesmas. Oleh karena itu, perlu dilakukan studi untuk melihat hubungan antara kelengkapan dan kecukupan jenis tenaga kesehatan dengan tingkat kinerja yang diukur melalui capaian SPM Bidang Kesehatan di puskesmas sehingga dapat dirumuskan kebijakan dan tindakan kepegawaian pada tingkat puskesmas dalam rangka meningkatkan capaian SPM Bidang Kesehatan.

\section{METODE PENELITIAN}

Penelitian ini menggunakan rancangan cross sectional dimana pengambilan data untuk setiap variabel dilakukan secara bersamaan. Teknik pengambilan sampel menggunakan total sampling dimana populasi dalam penelitian ini sebanyak 57 puskesmas yang berada di wilayah Kabupaten Cirebon.

Instrumen penelitian yang digunakan adalah checklist untuk melihat variable jenis, jumlah tenaga kesehatan dan capaian indicator kinerja SPM Bidang Kesehatan.Jenis tenaga kesehatan yang diidentifikasi sebanyak 9 jenis tenaga kesehatan yaitu dokter, dokter gigi, perawat, bidan, tenaga kesehatan masyarakat, tenaga kesehatan lingkungan, ahli teknologi laboratorium medis, tenaga gizi, dan tenaga kefarmasian. Jumlah tenaga kesehatan diidentifikasi setiap jenisnya berdasarkan standar yang ditetapkan dalam Peraturan menteri Kesehatan Nomor 75 Tahun 2014 tentang Puskesmas. Capaian indicator kinerja SPM Bidang Kesehatan diperoleh dari identifikasi realisasi cakupan $\mathrm{K} 4$, cakupan bumil dengan komplikasi yang ditangani, cakupan kunjungan bayi, cakupan desa universal child immunization, cakupan pelayanan anak balita, cakupan balita gizi buruk mendapat perawatan, cakupan penjaringan kesehatan siswa sd, cakupan peserta kb aktif, cakupan penemuan penderita pneumonia, cakupan penemuan penderita tb, cakupan penderita dbd yang ditangani, cakupan penemuan penderita diare, cakupan desa mengalami klb dan ditanggulangi, serta cakupan desa siaga aktif. Instrument yang digunakan tidakdilakukan ujicoba karena setiap butir pertanyaan dalam checklist langsung dapat mengidentifikasi isi setiap variable jenis dan jumlah tenaga kesehatan.

Penelitian ini menggunakan data sekunder yang diambil dari profil Dinas Kesehatan Kabupaten Cirebon 2016. Profil tersebut berisi realisasi capaian kegiatan, program, dan pelayanan yang sudah dilakukan oleh puskesmas yang berada di Kabupaten Cirebon.Data sekunder yang diambil dikelompokan berdasarkan variabel yang diteliti dan dituliskan dalam lembar checklist yang sudah dibuat.Variabel jenis tenaga kesehatan dikategorikan menjadi lengkap dan tidak lengkap berdasarkan 9 jenis tenaga kesehatan yang harus ada di puskesmas sedangkan variable jumlah tenaga kesehatan dikategorikan menjadi sesuai dan tidak sesuai berdasarkan jumlah tenaga pada setiap jenisnya. Pengolahan data dilakukan dengan bantuan program komputer.Analisis yang dilakukan berupa analisis univariabel dengan menyajikan distribusi frekuensi dari setiap variable dan analisis bivariabel untuk mengetahui hubungan antara variabel. Variabel penelitian ini berbentuk kategorik maka uji statistik yang digunakan adalah uji crosstabulation denganChi Square. Karena tidak memenuhi syarat untuk dilakukan uji Chi Square, maka dipilih uji alternative lainnya yaitu uji Fisher.

\section{HASIL PENELITIAN}

Data yang digunakan dalam penelitian ini bersumber dari profil kesehatan Kabupaten Cirebon tahun 2016. Profil tersebut berisi kondisi umum Kabupaten Cirebon meliputi luas wilayah, jumlah penduduk berdasarkan jenis kelamin, fasilitas pelayanan kesehatan baik milik pemerintahmaupun swasta, kondisi ketenagaan baik jenis dan jumlah tenaga kesehatan maupun tenaga non kesehatan berdasarkan fasilitas pelayanan kesehatan yang dimiliki pemerintah. Profil tersebut juga berisi realisasi capaian kegiatan, program, dan pelayanan yang sudah dilakukan oleh 57 puskesmas yang berada di Kabupaten Cirebon. Hasil analisis univariat dan bivariat adalah sebagai berikut: 
Tabel 1 Capaian Indikator Kinerja SPM Bidang Kesehatan, Jenis dan Jumlah Tenaga Kesehatan

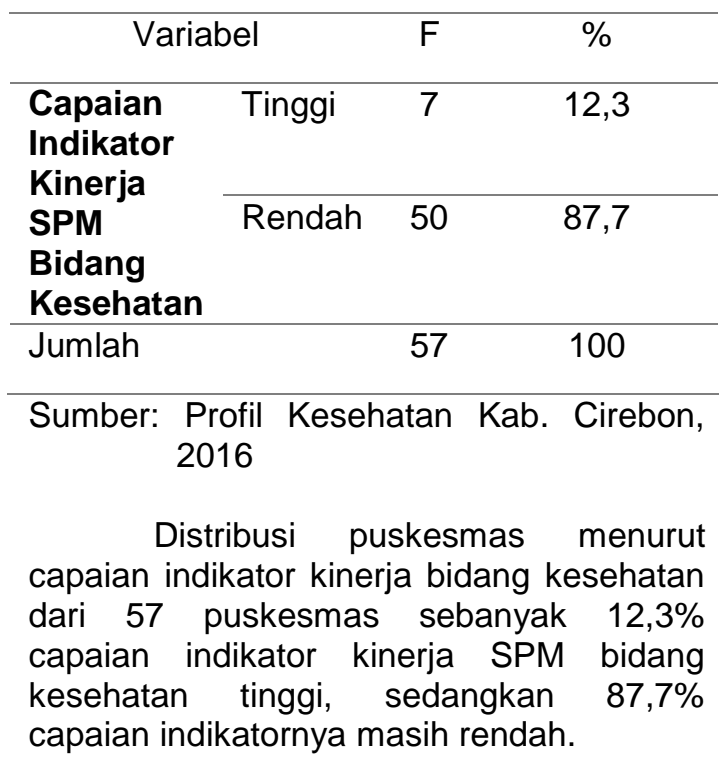

Tabel 2 Menunjukan bahwa dari 57 puskesmas yang dianalisis kelengkapan jenis tenaga kesehatannya diperoleh hasil sebagai berikut:

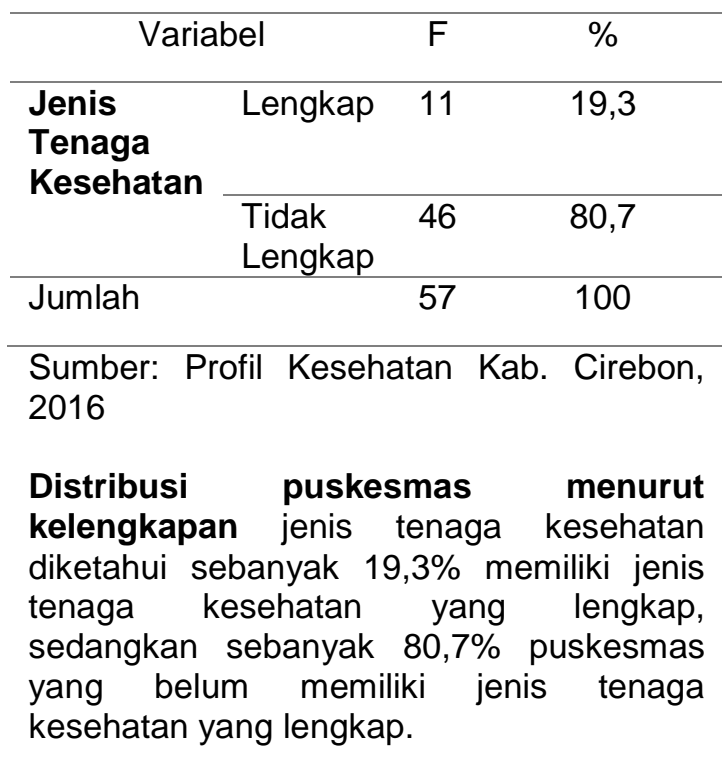

Tabel 3 Menunjukan bahwa dari 57 puskesmas yang dianalisis kecukupan jumlah tenaga kesehatannya diperoleh hasil sebagai berikut:

\begin{tabular}{|c|c|c|c|}
\hline \multicolumn{2}{|c|}{ Variabel } & $f$ & $\%$ \\
\hline \multirow{2}{*}{$\begin{array}{l}\text { Jumlah } \\
\text { Tenaga } \\
\text { Kesehatan }\end{array}$} & Sesuai & 4 & 7 \\
\hline & $\begin{array}{l}\text { Tidak } \\
\text { Sesuai }\end{array}$ & 53 & 93 \\
\hline Jumlah & & 57 & 100 \\
\hline
\end{tabular}

Sumber: Profil Kesehatan Kab. Cirebon, 2016

Distribusi puskesmas diketahui sebanyak $7 \%$ memiliki jumlah tenaga kesehatan yang lengkap sesuai dengan standar, sedangkan sebanyak 93\% puskesmas tidak lengkap memiliki jumlah tenaga kesehatan yang sesuai dengan standar. 
Tabel 4 Hubungan Jenis Tenga Kesehatan dengan Capaian Indikator Kinerja SPM Bidang Kesehatan

\begin{tabular}{|c|c|c|c|c|c|}
\hline \multicolumn{2}{|c|}{ Variabel } & \multicolumn{2}{|c|}{$\begin{array}{c}\text { Capaian Indikator Kinerja SPM } \\
\text { Bidang Kesehatan }\end{array}$} & \multirow[t]{2}{*}{ Jumlah } & \multirow{2}{*}{$\begin{array}{c}\text { Nilai } \\
p\end{array}$} \\
\hline & & Tinggi & Rendah & & \\
\hline \multirow[t]{2}{*}{$\begin{array}{l}\text { Jenis Tenaga } \\
\text { Kesehatan }\end{array}$} & Lengkap & $4(36,4 \%)$ & $7(63,3 \%)$ & $11(100 \%)$ & 0,021 \\
\hline & $\begin{array}{l}\text { Tidak } \\
\text { Lengkap }\end{array}$ & $3(6,5 \%)$ & $43(93,5 \%)$ & $46(100 \%)$ & \\
\hline Jumlah & & $7(12,3 \%)$ & $50(87,7 \%)$ & & \\
\hline
\end{tabular}

Sumber: Profil Kesehatan Kabupaten Cirebon, 2016

Keterangan: Tingkat kemaknaan $(\alpha=0,05)$

Tabel 4 menunjukan bahwa 11 puskesmas yang memiliki jenis tenaga kesehatan lengkap sebanyak $4(36,4 \%)$ puskesmas dapat mencapai indikator kinerja SPM bidang kesehatan tinggi, sedangkan $7(63,3 \%)$ puskesmas lainnya masih rendah. Sebanyak 46 puskesmas yang tidak lengkap jenis tenaganya diketahui $3(6,5 \%)$ puskesmas dapat mencapai indikator kinerja SPM bidang kesehatan yang tinggi, sedangkan43 (93,5\%) puskesmas masih rendah kinerjanya. Hasil uji fisher menunjukan nilai significancy ( $\mathrm{p}$ value) adalah 0,021 , dengan demikian dapat disimpulkan bahwa ada hubungan antara jenis tenaga kesehatan dengan capaian indikator kinerja SPM bidang kesehata

$\mathrm{n}$.

Tabel 5 Hubungan Jumlah Tenaga Kesehatan dengan Capaian Indikator Kinerja SPM Bidang Kesehatan

\begin{tabular}{|c|c|c|c|c|c|}
\hline \multirow{2}{*}{\multicolumn{2}{|c|}{ Variabel }} & \multicolumn{2}{|c|}{$\begin{array}{l}\text { Capaian Indikator Kinerja } \\
\text { SPM Bidang Kesehatan }\end{array}$} & \multirow[t]{2}{*}{ Jumlah } & \multirow[b]{2}{*}{ Nilai $p$} \\
\hline & & Tinggi & Rendah & & \\
\hline \multirow{2}{*}{$\begin{array}{l}\text { Jumlah } \\
\text { Tenaga } \\
\text { Kesehatan }\end{array}$} & Sesuai & $3(75 \%)$ & $1(25 \%)$ & $4(100 \%)$ & 0,005 \\
\hline & Tidak Sesuai & $4(7,5 \%)$ & $49(92,5 \%)$ & 53 (100\%) & \\
\hline Jumlah & & $7(12,3 \%)$ & $50(87,7 \%)$ & & \\
\hline
\end{tabular}

Sumber: Profil Kesehatan Kabupaten Cirebon, 2016

Keterangan: Tingkat kemaknaan $(\alpha=0,05)$

Tabel 5 menunjukan bahwa 4 puskesmas yang memiliki jumlah tenaga kesehatan sesuai standar sebanyak 3 (75\%) puskesmas dapat mencapai indikator kinerja SPM bidang kesehatan yang tinggi, sedangkan sebanyak 1 (25\%) puskesmas masih rendah kinerjanya. Sebanyak 53 puskesmas yang memiliki jumlah tenaga kesehatan tidak sesuai dengan standar diketahui 4 (7,5\%) puskesmas dapat mencapai indikator kinerja SPM bidang kesehatan yang tinggi sedangkan 49 (92,5\%) puskesmas masih rendah kinerjanya. Hasil uji Fisher menunjukan bahwa nilai significancy(p value) adalah 0,005, dengan demikian dapat disimpulkan bahwa ada hubungan antara jumlah tenaga kesehatan dengan capaian indikator kinerja SPM bidang kesehata. 


\section{PEMBAHASAN}

Hasil penelitian menunjukan bahwa puskesmas di Kabupaten Cirebon yang dikategorikan memiliki capaian indikator kinerja tinggi masih sedikit. Sebagian besar puskesmas masih dikategorikan memiliki tingkat capaian kinerja yang rendah. Hal ini sejalan dengan hasil penelitian lain yang menemukan bahwa sebagian besar puskesmas di Kabupaten Bojonegoro belum mencapai target indikator Standar Pelayanan Minimal (SPM).

Tingkat pencapaian indikator kinerja SPM bidang kesehatan sangat dipengaruhi oleh komitmendari pemerintah daerah untuk melaksanakannya. Ada pemerintah daerah yang memiliki komitmen tinggi namun ada juga daerah yang masih kesulitan menterjemahkan SPM Bisang Kesehatan dalam bentuk program dan kegiatan serta implementasi di lapangan. Sebagaimana menurut hasil penelitian yang menyatakan bahwa Implementasi Standar Pelayanan Minimal Bidang Kesehatan (SPM-BK) Kabupaten/Kota di masing-masing kabupaten/kota menunjukkan adanya perbedaan pencapaian, baik dalam hal cakupan maupun di dalam pemahaman mengenai definisi operasional dan pengertian yang terkandung di dalam setiap indikator SPM-BK. Perbedaan juga terjadi dalam tataran operasional, dimana ada kabupaten/kota yang sudah menerapkannya di dalam suatu payung hukum tertentu di tingkat daerah, melakukan advokasi, menyusun rancangan anggaran berbasis SPM, namun ada juga kabupaten/kota yang belum banyak bersikap terkait implementasi SPM-BK.

SPM bidang kesehatan adalah tolok ukur kinerja pelayanan kesehatan yang diselenggarakan oleh daerah kabupaten/kota. Target cakupan SPM kesehatan ini sebagian daerah mencapai $100 \%$ dan sisanya mendekati angka $100 \%$. Hal ini merupakan sebuah target yang tidak mudah dicapai, dibutuhkan kesungguhan dan rencana yang matang dalam upaya pencapaiannya [7]. Pencapaian target SPM bidang kesehatan membutuhkan komitmen tinggi dari pemerintah daerah yang harus diwujudkan dalam perencanaan program dan kegiatan daerah.
Indikator - indicator kinerja dalam SPM bidang kesehatan diwujudkan dalam bentuk pelayanan- pelayanan kesehatan di puskesmas. Ketersediaan jenis dan jumlah sumber daya manusia yang cukup dapat mendorong terselenggaranya pelayanan kesehatan dengan baik. Jenis tenaga kesehatan minimal yang harus ada di puskesmas berjumlah sembilan (9) jenis tenaga antara lain: dokter, dokter gigi, perawat, bidan, kesehatan masyarakat, kesehatan lingkungan, tenaga kefarmasian, tenaga gizi, dan ahli teknologi laboratorium medik.

Hasil penelitian menunjukan bahwa masih banyak puskesmas di Kabupaten Cirebon yang belum lengkap jenis tenaga kesehatannya sebagaimana ketentuan yang dipersyaratkan oleh kementerian kesehatan. Hanya sebagian kecil puskesmas saja yang telah lengkap memiliki 9 jenis tenaga kesehatan, sedangkan sebagian besarnya belum lengkap memiliki jenis tenaga kesehatan. Namun ada beberapa jenis tenaga kesehatan yang semua puskesmas di Kabupaten Cirebon telah memilikinya yaitu perawat dan bidan.

Kelengkapan jenis dan kecukupan jumlah tenaga kesehatan akan sangat mendukung terhadap berjalannya fungsifungsi pelayanan di puskesmas. Semua jenis personel kesehatan harus menjadi perhatian pemimpin. Hal ini perlu mendapat perhatian yang serius agar fungsi organisasi seperti puskesmas dapat berjalan dengan optimal.

Hasil analisis bivariabel menunjukan ada hubungan jenis tenaga kesehatan dengan capaian indikator kinerja SPM bidang kesehatan. Hal ini sesuai dengan hasil penelitian lain yang menunjukan bahwa ada hubungan yang bermakna antara variabel jenis tenaga bidan, dokter, dan apoteker dengan rata-rata capaian indikator kinerja SPM bidang kesehatan di $\mathrm{Kab} / \mathrm{Kota}$ yang terkategorisasi daerah terpencil perbatasan dan kepulauan (DTPK).

Berdasarkan ketentuan Peraturan Menteri Kesehatan Nomor 75 Tahun 2014 tentang Puskesmas disebutkan bahwa pendirian puskesmas juga harus memenuhi persyaratan salah satunya adalah 
kelengkapan jenis dan kecukupan jumlah tenaga kesehatan. Jenis tenaga kesehatan minimal yang harus ada di puskesmas berjumlah sembilan (9) jenis yang meliputi: dokter, dokter gigi, perawat, bidan, tenaga kesehatan masyarakat, tenaga kesehatan lingkungan, tenaga kefarmasian, tenaga gizi, dan ahli laboratorium medik.

Hasil analisis bivariabel menunjukan ada hubunganyang bermakna antara jumlah tenaga kesehatan dengan capaian indikator kinerja SPM bidang kesehatan. Hasil penelitian lain juga menunjukan bahwa ada hubungan antara jumlah tenaga kesehatan perawat dan bidan dengan capaian indikator kinerja SPM Kab/Kota [10]. Menurut ketentuan Peraturan Menteri Kesehatan Nomor 75 Tahun 2014 tentang Puskesmas disebutkan bahwa pemerintah menetapkan jumlah minimal tenaga kesehatan untuk setiap jenis dan kategori puskesmas antara lain: Puskesmas Kawasan Perkotaan Non Rawat Inap minimal jumlah dokter 1 orang, dokter gigi 1 orang, perawat 5 orang, bidan 4 orang, tenaga kesehatan masyarakat 2 orang, tenaga kesehatan lingkungan 1 orang, ahli teknologi laboratorium medik 1 orang, tenaga gizi 1 orang, tenaga kefarmasian 1 orang, tenaga administrasi 3 orang, pekarya 2 orang. Puskesmas Kawasan Perkotaan Rawat Inap minimal jumlah dokter 2 orang, dokter gigi 1 orang, perawat 8 orang, bidan 7 orang, tenaga kesehatan masyarakat 2 orang, tenaga kesehatan lingkungan 1 orang, ahli teknologi laboratorium medik 1 orang, tenaga gizi 2 orang, tenaga kefarmasian 2 orang, tenaga administrasi 3 orang, pekarya 2 orang. Puskesmas Kawasan Pedesaan Non Rawat Inap minimal jumlah dokter 1 orang, dokter gigi 1 orang, perawat 5 orang, bidan 4 orang, tenaga kesehatan masyarakat 1 orang, tenaga kesehatan lingkungan 1 orang, ahli teknologi laboratorium medik 1 orang, tenaga gizi 1 orang, tenaga kefarmasian 1 orang, tenaga administrasi 2 orang, pekarya 1 orang. Puskesmas Kawasan Pedesaan Rawat Inap minimal jumlah dokter 2 orang, dokter gigi 1 orang, perawat 8 orang, bidan 7 orang, tenaga kesehatan masyarakat 1 orang, tenaga kesehatan lingkungan 1 orang, ahli teknologi laboratorium medik 1 orang, tenaga gizi 2 orang, tenaga kefarmasian 1 orang, tenaga administrasi 2 orang, pekarya 1 orang. Dengan demikian standar ketenagaan tersebut merupakan kondisi minimal yang harus dipenuhi agar puskesmas dapat terselenggara dengan baik. Hal ini menunjukan jumlah tenaga kesehatan yang ada akan menentukan penyelenggaraan pelayanan kesehatan di puskesmas.

\section{SIMPULAN DAN SARAN}

Hasil penelitian dapat disimpulkan bahwa proporsi puskesmas yang memiliki tingkat kinerja pencapaian SPM bidang kesehatan tinggi masih sedikit (12,3\%). Proporsi puskesmas yang memiliki jenis tenaga kesehatan lengkap masih sedikit $(19,3)$.Proporsi puskesmas yang memiliki kesesuaian jumlah tenaga kesehatan dengan standar masih sedikit (7\%). Selain itu diketahui pula ada hubungan yang bermakna antara jenis dan jumlah tenaga kesehatan dengan capaian indikator kinerja SPM bidang kesehatan.

Berdasarkan kesimpulan tersebut pemerintah Kabupaten Cirebon dalam menempatkan tenaga kesehatan harus memperhatikan kelengkapan dalam hal jenis dan kecukupan dalam hal jumlah di setiap puskesmas agar cakupan indikator pelayanan kesehatan di puskesmas dapat ditingkatkan.

\section{DAFTAR PUSTAKA}

\section{S. Atiningtyas. (2012). "Pengukuran Kinerja Puskesmas Berdasarkan Keputusan Menteri Kesehatan RI Nomor 828/MENKES/SK/IX/2008 Di Kabupaten Bojonegoro," Jurnal Akuntansi UNESA Volume 1.}

A. D. Laksono, E. Sopacua, Suharmiati, L. Handayani, Ristrini, H. Maryani and B. Wasito. (2010). Standar Pelayanan Minimal Kesehatan: Sebuah Panduan Formulasi di Tingkat Puskesmas/Kecamatan, Surabaya: Health Advocacy Yayasan Pemberdayaan Kesehatan Masyarakat. 
Kementerian Kesehatan RI. (2014).

Peraturan Menteri Kesehatan RI Nomor 75

Tahun 2014 tentang Pusat Kesehatan

Masyarakat, Jakarta: Kementerian

Kesehatan RI.

Y. Ilyas. (2012). Perencanaan SDM Rumah Sakit, Jakarta: FKM UI.

R. Husein. (2013). "Studi Evaluasi

Ketersediaan Tenaga Kesehatan di

Puskesmas Pada Kabupaten/Kota Daerah

Tertinggal, Perbatasan dan Kepulauan

Terhadap Capaian Indikator Kinerja

Standar Pelayanan Minimal

Kabupaten/Kota," Fakultas Kesehatan

Masyarakat Universitas Indonesia, Jakarta.

H. Hendarwan and Rosita. (2015). "Analisis Implementasi Standar Pelayanan Minimal

Bidang Kesehatan Kabupaten/Kota," Jurnal

Ekologi Kesehatan Volume 14, pp. 367 -

380.

Kementerian Kesehatan RI. (2015).
Rencana Strategis Kementerian Kesehatan RI Tahun 2015 - 2019, Jakarta:

Kementerian Kesehatan RI.

Kementerian Kesehatan RI. (2012). Laporan Akhir Riset Fasilitas Kesehatan 2011 (Puskesmas), Jakarta: Kementerian Kesehatan RI.

Republik Indonesia. (2005). Peraturan Pemerintah Nomor 65 Tentang Standar Pelayanan Minimal, Jakarta: Republik Indonesia.

Kementerian Kesehatan RI, Kamis September 2017. [Online]. Available: http://www.spm.depkes.go.id/index3.php. 